\title{
Magnesium metabolism in type 2 diabetes mellitus, metabolic syndrome and insulin resistance
}

\author{
Mario Barbagallo*, Ligia J. Dominguez \\ Institute of Internal Medicine and Geriatrics, University of Palermo, Italy
}

Received 10 January 2006, and in revised form 10 May 2006

Available online 12 June 2006

\begin{abstract}
Type 2 diabetes is characterized by cellular and extracellular Mg depletion. Epidemiologic studies showed a high prevalence of hypomagnesaemia and lower intracellular $\mathrm{Mg}$ concentrations in diabetic subjects. Insulin and glucose are important regulators of $\mathrm{Mg}$ metabolism. Intracellular $\mathrm{Mg}$ plays a key role in regulating insulin action, insulin-mediated-glucose uptake and vascular tone. Reduced intracellular $\mathrm{Mg}$ concentrations result in a defective tyrosine-kinase activity, post-receptorial impairment in insulin action, and worsening of insulin resistance in diabetic patients. Mg deficit has been proposed as a possible underlying common mechanism of the "insulin resistance" of different metabolic conditions. Low dietary Mg intake is also related to the development of type 2 diabetes. Benefits of Mg supplementation on metabolic profile in diabetic subjects have been found in most, but not all clinical studies, and larger prospective studies are needed to support the potential role of dietary $\mathrm{Mg}$ supplementation as a possible public health strategy in diabetes risk.
\end{abstract}

(C) 2006 Elsevier Inc. All rights reserved.

Keywords: Magnesium; Glucose intolerance; Type 2 diabetes; Hypertension; Insulin resistance; Ionized magnesium; Ions; Diabetes mellitus; Glucose; Metabolic syndrome

Magnesium (Mg) is the second most abundant intracellular cation after potassium present in living cells. Of the $21-28 \mathrm{~g}$ of $\mathrm{Mg}$ present in the adult human body, $99 \%$ is distributed in the intracellular compartment, and only $1 \%$ in the extracellular fluid. $\mathrm{Mg}$ is subdivided into three major compartments of the body: about $65 \%$ in the mineral phase of skeleton, $34 \%$ in the intracellular space, and only $1 \%$ in the extracellular fluid [1]. Small intestine is the main site for $\mathrm{Mg}$ absorption, whereas $\mathrm{Mg}$ excretion is mainly performed through renal pathways. Serum Mg exists in three forms: a protein-bound fraction (25\% bound to albumin and $8 \%$ bound to globulins), a chelated fraction $(12 \%)$, and the metabolically active ionized fraction (Mg-ion: 55\%) [2]. The levels of $\mathrm{Mg}$ in the plasma of healthy people are extremely constant, with a reference interval for total serum levels of $0.75-0.96 \mathrm{mmol} / \mathrm{L}$, and a mean of $0.85 \mathrm{mmol} / \mathrm{L}$. One of the

\footnotetext{
* Corresponding author. Fax: +390916552952.

E-mail address: mabar@unipa.it (M. Barbagallo).
}

main reasons that $\mathrm{Mg}$ metabolism has not become more the focus of routine attention in clinical practice has been the difficulties in obtaining an easily available, accurate, and reproducible measure of $\mathrm{Mg}$ status. Total serum concentrations $(\mathrm{MgT})$ do not reflect the $\mathrm{Mg}$ status or intracellular pool, and intracellular (Mgi) or serum ionized (Mg-ion) $\mathrm{Mg}$ depletion can be seen with normal $\mathrm{MgT}$ concentrations $[3,4] .{ }^{31} \mathrm{P}$ NMR spectroscopic techniques, although remaining a research based test, are completely noninvasive and are at present time in 2006 the gold standard for intracellular measurements of free $\mathrm{Mg}$ content in living tissues in situ $[5,6]$. For routine clinical use, the development of $\mathrm{Mg}$-specific ion-selective electrodes (ISE) has been particularly useful, allowing to measure extracellular free levels of $\mathrm{Mg}$, with a higher sensitivity than $\mathrm{MgT}$ in detecting subclinical $\mathrm{Mg}$ deficits in several clinical conditions, such as diabetes $[3,4]$.

Although no known hormonal factor is specifically involved in the regulation of $\mathrm{Mg}$ metabolism, many hormones are recognized to have an effect on $\mathrm{Mg}$ balance and 
transport. Among them, parathormone and calcitonin play a major role, and catecholamines also influence Mg metabolism [7]. A role for insulin has been proposed, and accumulating data have confirmed that insulin is a key hormone in the regulation of the $\mathrm{Mg}$ metabolism [1,8].

\section{Insulin as a regulatory hormone of magnesium metabolism}

Insulin has specific ionic effects to stimulate the transport of $\mathrm{Mg}$ from the extracellular to the intracellular compartment, thus increasing Mgi content [9]. Using gold standard NMR techniques to measure Mgi in vitro in erythrocyte from nondiabetic healthy individuals, we have showed an ionic action of insulin that is specific, doserelated, and independent of cellular glucose uptake [9-11]. The mechanism by which insulin acutely increases Mgi content is still in question. Insulin might induce alterations in ion fluxes, particularly by stimulating the $\mathrm{Na}^{+} / \mathrm{H}^{+}$antiporter either directly or via diacylglycerol-protein-kinase $\mathrm{C}$ [10], or by inhibiting Ca-ATPase activity [11]. Furthermore, there are indications that, as in other energy-producing systems, an ATPase dependent pump is involved in the mechanism by which insulin regulates erythrocyte $\mathrm{Mg}$ content. The insulin-mediated Mgi accumulation may depend upon the activation of the tyrosine-kinase insulin receptor since the insulin effect on intracellular $\mathrm{Mg}$ is totally abolished by a monoclonal antibody directed towards the insulin receptor [12]. Furthermore, there are indications that, as in other energy producing systems, an ATPase-dependent pump is involved in the mechanism by which insulin regulates the erythrocyte $\mathrm{Mg}$ content.

\section{Magnesium as a modulator of insulin action and insulin sensitivity}

The relationship between insulin and $\mathrm{Mg}$ is a complex one. Insulin regulates $\mathrm{Mg}$ homeostasis but, in turn, $\mathrm{Mg}$ itself is a major determinant of insulin and glucose metabolism. An increasing number of evidences have suggested a clinical relevance for the altered $\mathrm{Mg}$ metabolism present in states of increased peripheral insulin resistance. $\mathrm{Mg}$ is a necessary cofactor in over 300 enzymatic reactions and specifically in all phosphorylation processes, and in general in all reactions that involve the utilization and transfer of ATP, including cellular responses to growth factors and cell proliferation [13,14]. Mg-ion, although not directly involved in the biochemical process of contraction, modulates vascular smooth muscle tone and contractility by affecting calcium ion concentrations and its availability at critical sites. Mg-ions directly influence baseline tension, vascular tone, and vascular responsiveness to pressor agents [15]. Diabetes or insulin resistance causes a significant impairment in the relaxation responses to $\mathrm{Mg}$ and aggravates the alteration in Mg-induced vascular relaxation observed in pregnancy [16].

Intracellular $\mathrm{Mg}$ is a critical cofactor for several enzymes in carbohydrate metabolism, and because of its role as part of the activated Mg-ATP complex required for all of the rate-limiting enzymes of glycolysis, regulates the activity of all enzymes involved in phosphorylation reactions. Mg concentration is critical in the phosphorylation of the tyrosinekinase of the insulin receptor as well as all other proteinkinases, all ATP and phosphate transfer-associated enzymes, such as the Ca-ATPases in plasma membrane and endoplasmic reticulum. $\mathrm{Mg}$ deficiency may result in disorders of tyrosine-kinase activity on the insulin receptor, event related to the development of post-receptorial insulin resistance and decreased cellular glucose utilization [17] that is, the lower the basal $\mathrm{Mg}$, the greater the amount of insulin required to metabolize the same glucose load, indicating decreased insulin sensitivity. Specifically, in skeletal [18] and in heart [19] muscle and fat tissue [20], insulin resistance would be the expected outcome in the presence of suppressed cellular Mg. As such, in mouse skeletal muscle increased $\mathrm{Mg}$ efflux from cells was associated with inhibition of insulin-stimulated glucose uptake. Significant decrements in the insulin signaling enzyme activities can already be observed at the range of $\mathrm{Mg}$ values seen in disease states such as type 2 diabetes mellitus and hypertension [21]. Determination of intracellular free $\mathrm{Mg}$ concentrations using ${ }^{31} \mathrm{P}$ NMR has revealed that cellular concentrations of Mgi are in the $100-300 \mathrm{nM}$ range, which is close to the dissociation constant of many enzymes systems using ATP or phosphate transfer. Since tissue $\mathrm{Mg}$ uptake is regulated by insulin, then impairment of this process by insulin resistance could either cause or exacerbate intracellular Mg deficiency.

\section{Glucose as physiologic determinant of cellular magnesium}

Glucose appears to contribute to cellular ion homeostasis independently of insulin. The role of hyperglycemia in the intracellular $\mathrm{Mg}$ depletion of diabetes has been confirmed by research from our group indicating that hyperglycaemia both in vivo after oral glucose loading [22] and in vitro, independently of insulin or other in vivo responses to oral glucose ingestion [23,24], directly induces suppression of Mgi. Specifically, the transient hyperglycemia of oral glucose loading reproduces in normal subjects the same altered ionic profile of depleted Mgi/increased Cai levels that occurs chronically in diabetic subjects [25], which dynamically appears to be equally and inversely true for serum ionized $\mathrm{Mg}$ [22]. This glucose-mediated ionic effects are independent of insulin action, since hyperglycemia induces ionic changes both in VSMC [26], and in red cells $[23,24]$, where glucose transport is unaffected by insulin, and are clinically significant since they occur at glucose concentrations achieved clinically $(10 \mathrm{mM})$, in vivo in subjects with impaired glucose tolerance as well as frank diabetes mellitus. Since hyperglycemia per se significantly contributes to insulin resistance in diabetes mellitus [27] and because reducing Mgi promotes vasoconstriction [28], it is possible to hypothesize a role of this glucose-induced $\mathrm{Mg}$ changes in the vasoconstriction present in chronic 
diabetic states $[1,8,29]$. The previously reported relations of fasting blood glucose and $\mathrm{HbAlc}$ levels (reflective of average glycemic levels over time in diabetic subjects) to cellular ion levels support the clinical significance of these in vitro glucose induced changes [1,30,31], suggesting that circulating glucose concentrations, even within the "normal" range, may be a physiologic determinant of cytosolic $\mathrm{Mg}$ concentrations.

\section{Cellular magnesium as a determinant of "Ionic Insulin Resistance" and cellular responsiveness}

The overall hypothesis that Mgi content is a crucial determinant of cellular responsiveness is supported by data showing that the ability of insulin and glucose at physiologically maximal concentrations to stimulate Mgi is impaired in cells, in which the basal $\mathrm{Mg}$ content is reduced. The in vitro glucose-independent ionic effects of insulin are blunted in cells with a reduced basal Mgi content [32]. Continuous relationships were observed between basal Mgi values and Mgi responses to insulin, i.e., the lower the basal Mgi, the less responsive is the cell to insulin stimulation, confirming that insulin action is strictly dependent from the cellular Mgi concentration. Similarly, altered cellular behavior was found in cells responsiveness to glucose action. Glucose-induced changes in Mgi levels were closely related to basal Mgi levels. For all subjects cellular $\mathrm{Mg}$ responsiveness to insulin or glucose was closely and directly related to basal Mgi levels - the lower the basal Mgi, the less the Mgi rose in response to insulin (or glucose) [32]. These results confirm that although Mgi levels may be regulated by ambient glucose and insulin levels, in turn, basal Mgi environment influences the cellular ionic responses to insulin and glucose. These data also provide at least one mechanism - the lowering of intracellular free Mgi, by which hyperglycemia itself contributes to insulin resistance.

One question arising from these observations was whether this cellular ionic resistance to insulin reflected a unique abnormality of cellular insulin action or whether it represented a more general property of cells, in which cellular $\mathrm{Mg}$ deficiency necessarily also alters cellular ionic responses to other nonhormonal stimuli as well. Thus, following an oral glucose tolerance test, the rate of glucose disappearance from the circulation was inversely related to the basal skeletal muscle free $\mathrm{Mg}$ content in the same manner - the lower the Mgi, the slower the decrease in extracellular glucose and the more blunted the $\mathrm{Mg}$ uptake (unpublished data). This is consistent with an a priori cellular $\mathrm{Mg}$ deficiency as the cause of, rather than merely the result of, peripheral insulin resistance [22]. The primacy of Mgi levels in determining insulin action, rather than vice versa, was also suggested by the induction of cellular insulin resistance in normal cells following intracellular $\mathrm{Mg}$ depletion to levels observed in hypertensive or diabetic cells [32]. Hence, regardless of the primary origins of glucose intolerance and insulin resistance in syndromes such as hypertension or diabetes, it is emphasized the potential con-

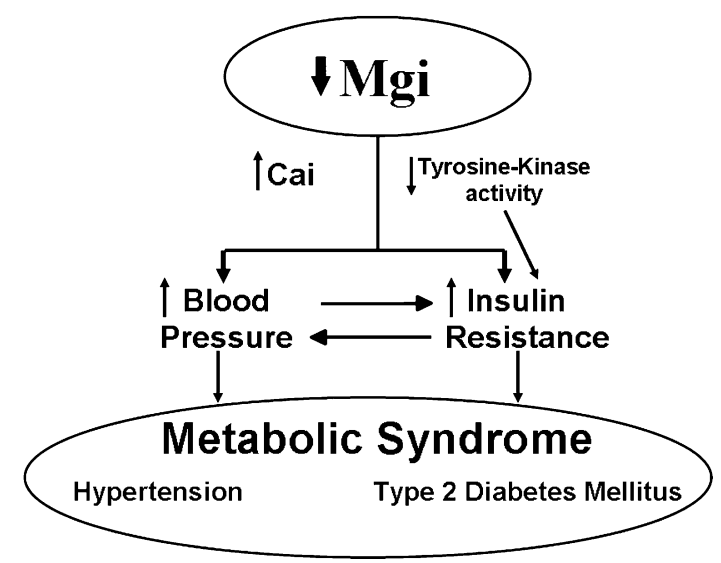

Fig. 1. Overall hypothesis in which intracellular Mg deficiency may mediate the relationship between insulin resistance, hypertension, metabolic syndrome, and type 2 diabetes mellitus.

tribution of altered cellular Mgi as an independent determinant of glucose and insulin action. Decreasing Mgi in cells from normal individuals rendered them resistant to the ionic effects of insulin, an effect indistinguishable from the insulin resistance observed in cells from hypertensive subjects [32]. Altogether, these data demonstrating ionic aspects of cellular insulin resistance has led us to hypothesize that the "insulin resistance", currently defined by measurements of tissue glucose uptake, might equally well be defined on the basis of altered cellular ion responsiveness. These data support the overall hypothesis that the intracellular ionic milieu is at least one determinant of physiological cellular responsiveness to extracellular stimuli. Thus, the "ionic" insulin resistance is probably not specific for insulin, but may rather be one tissue manifestation of a general property of cells in which steady-state Mgi may determine cell responsiveness to insulin, glucose or to other external stimuli. The relevance of altered cellular $\mathrm{Mg}$ metabolism to tissutal insulin sensitivity suggest a critical role of $\mathrm{Mg}$ in contributing to the clinical coincidence of $\mathrm{Mg}$ depletion to states of insulin resistance such as hypertension, metabolic syndrome, type 2 diabetes as well with the increased incidence of each of these conditions with age, a condition itself characterized by a tendency to $\mathrm{Mg}$ depletion. Thus, Mgi depletion can directly promote tissutal insulin resistance and altered vascular tone, thus helping to understand the mechanisms underlying the clinical association among these apparently disparate conditions (Fig. 1).

\section{Magnesium deficiency in type 2 diabetes mellitus}

Diabetes is frequently associated with both extracellular and intracellular $\mathrm{Mg}$ depletion. Epidemiologic studies have found an high prevalence of hypomagnesaemia in subjects with type 2 diabetes, especially in those with poorly controlled glycemic control [3,33-36]. In diabetic subjects, plasma Mg levels are inversely correlated to the metabolic control [33]. Because of the lack of sensitivity of MgT, a depletion in intracellular and serum ionized $\mathrm{Mg}$ can be 
found in many subjects with total serum $\mathrm{Mg}$ still in the normal range. Using the Nova- $8 \mathrm{Mg}$ ion-selective electrode (ISE) to measure serum ionized $\mathrm{Mg}$ in a preliminary sample of 50 subjects with type 2 diabetes, we have recently found significantly lower $\mathrm{Mg}$-ion levels compared to normal controls $(0.49+0.01 \mathrm{mmol} / \mathrm{L}$ vs. $0.52+0.01 \mathrm{mmol} / \mathrm{L}, p<0.05)$, without significant changes in MgT (Fig. 2). Resnick et al. measured concurrently MgT, Mg-ion and Mgi levels in the same subjects using ${ }^{31} \mathrm{P}$ NMR and the ISE Mg-selective electrode, and found that only both Mgi and Mg-ion (but not serum total $\mathrm{MgT}$ ) were significantly reduced diabetic subjects, and that a close direct relationship was present between the ionized extra and the intracellular Mg measurement [3].

Among the mechanisms that may favor $\mathrm{Mg}$ depletion in diabetes the most important are a low $\mathrm{Mg}$ intake and an increased $\mathrm{Mg}$ urinary loss, while dietary $\mathrm{Mg}$ absorption and retention are not impaired in patients with type 2 diabetes [37]. With regard to low Mg intake, changes in dietary habits in the western world have resulted in daily $\mathrm{Mg}$ intake close to, or even below, the recommended daily allowances. The ARIC study found a significant inverse correlation between dietary $\mathrm{Mg}$ and the incidence of type 2 diabetes[38]. Diabetes is associated with renal calcium and $\mathrm{Mg}$ wasting $[39,40]$, but the molecular mechanisms of these defects are unknown [41]. Plasma Mg levels were found inversely correlated with the urinary $\mathrm{Mg}$ excretion rate and with fasting blood glucose values, suggesting that the tubular reabsorption of $\mathrm{Mg}$ is decreased in presence of severe hyperglycemia [39]. An increased renal $\mathrm{Mg}$ transporter abundance was found in STZ-induced diabetic rats that may represent a compensatory adaptation for the increased load of $\mathrm{Mg}$ to the distal tubule. Insulin administration completely corrected the hyperglycemia-associated hypercalciuria and hypermagnesiuria, and reversed the increase of $\mathrm{Mg}$ transporter abundance [41]. An improved metabolic control was associated with reduced urinary $\mathrm{Mg}$ losses [35]. Hyperinsulinemia per se may also contribute to the urinary $\mathrm{Mg}$ depletion [40] and the reduced sensitivity to insulin may itself affect $\mathrm{Mg}$ transport. As additional factors, hyperglycemia in the absence of a good metabolic control may have a

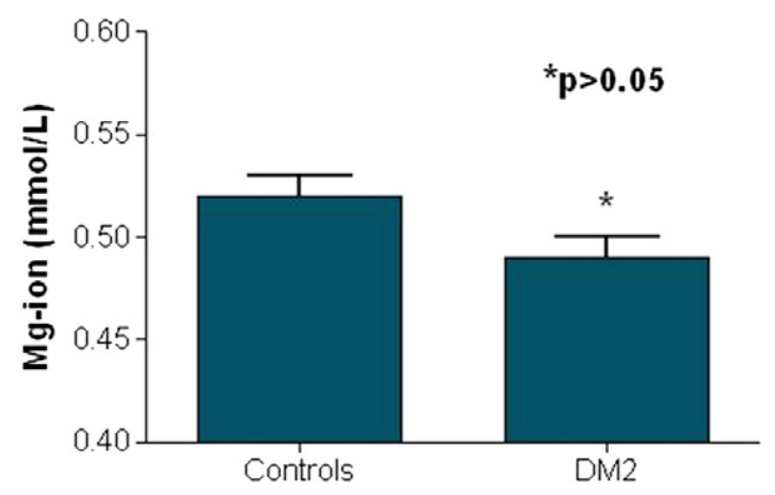

Fig. 2. Ionized $\mathrm{Mg}$ levels (Mg-ion, mmol/L) in type 2 diabetic subjects vs. normal controls. role in the increased urinary $\mathrm{Mg}$ excretion, and the use of loop and thiazide diuretics also promote $\mathrm{Mg}$ wasting.

At the cellular level, cytosolic free Mgi levels are consistently reduced in subjects with type 2 diabetes mellitus [25,30,42-44]. Using gold standard NMR techniques, our group have shown significantly lower steady-state Mgi and reciprocally increased Cai levels in subjects with type 2 diabetes, compared with young nondiabetic subjects $[25,30]$ (Fig. 3).

An alteration of the basal and cation-stimulated $\mathrm{Mg}^{2+}$ fluxes and transport across the plasma membrane [45] and of the $\mathrm{Na}^{+} / \mathrm{Mg}^{2+}$ exchanger [46], which could extrude but not accumulate $\mathrm{Mg}$ in exchange for $\mathrm{Na}$ has been found in diabetic liver cells [47]. The impairment of $\mathrm{Mg}$ uptake mechanism, in addition to the decrease in cellular ATP level, may contribute, at least in part, to explaining the decrease in cellular $\mathrm{Mg}$ content observed under diabetic conditions.

Mgi depletion in diabetes has been shown to be clinically and pathophysiologically significant, since Mgi levels quantitatively and inversely predict the fasting and post glucose levels of hyperinsulinemia, as well as peripheral insulin
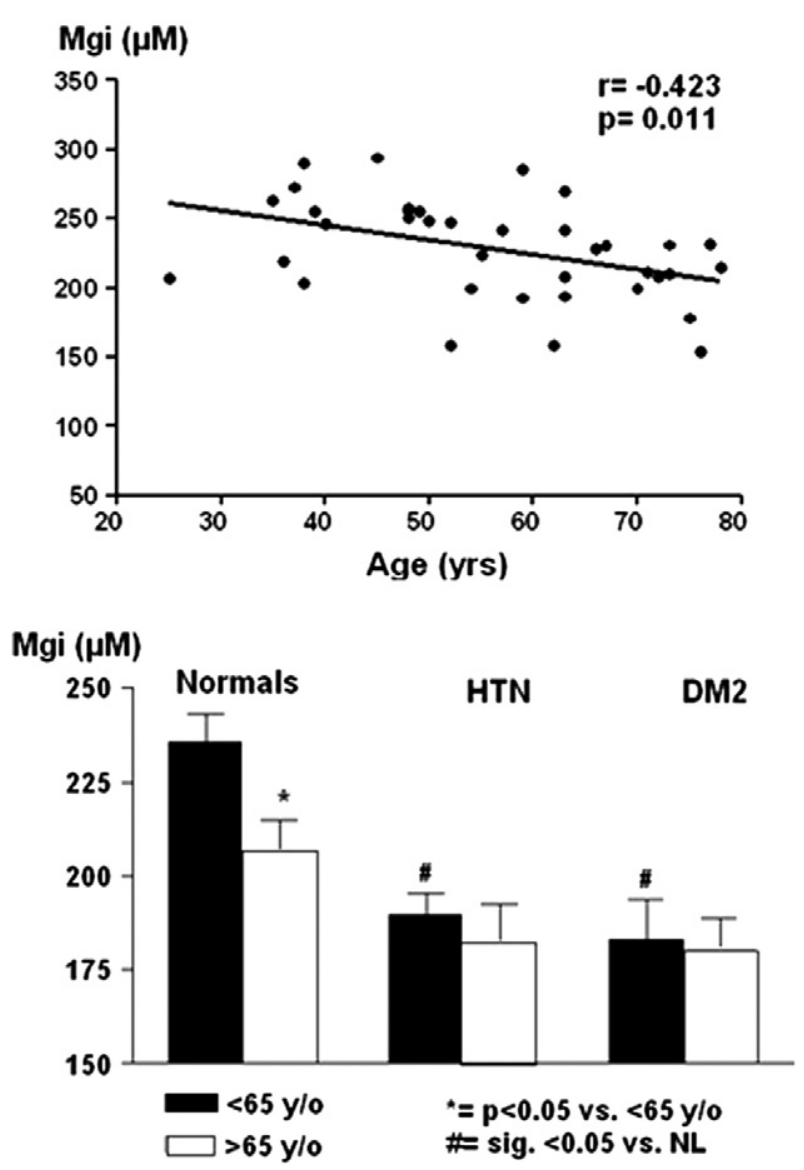

Fig. 3. Upper panel: relationship between age and cytosolic free magnesium (Mgi) levels in healthy normotensive nondiabetic subjects. Lower panel shows the effect of age on Mgi levels in healthy normals, in hypertensive (HTN) and in type 2 diabetic (DM2) subjects. Full bars indicate data from young-middle age subjects $(<65$ yo $)$ and empty bars indicate data from old age subjects ( $>65$ yo) (Ref. [32]). 
sensitivity, and both systolic and diastolic blood pressures [6,48]. Specifically, (a) fasting insulin levels [25,49]; (b) the integrated insulinemic response to a standard oral glucose tolerance test [49]; (c) the steady-state plasma glucose response to insulin infusion and indices for peripheral insulin sensitivity derived from euglycemic hyperinsulinemic clamps [50,51], are all inversely related to $\mathrm{Mg}$ levels, whether measured as Mgi in situ in brain, free or total $\mathrm{Mg}$ in peripheral red cells [8,49,51,22]or even as circulating Mg [52]. Furthermore, direct and inverse relations, respectively, are observed between steady-state fasting levels of Mgi and fasting blood glucose, blood pressure, HbAlc, and the glycemic and insulinemic response to oral glucose loading in normal, hypertensive, and diabetic subjects - the lower the Mgi, the higher the blood pressure and the more hyperinsulinemic the response to oral glucose loading $[25,30,49,31,53]$.

Aging is frequently associated with insulin resistance and glucose intolerance. We have specifically studied the behavior of ion content with age and have showed a continuous age-dependent fall of Mgi levels in peripheral blood cells of healthy elderly subjects, these alterations being indistinguishable from those occurring, independently of age, in essential hypertension or type 2 diabetes [30]. In other terms, essential hypertension and/or type 2 diabetes appear to determine an acceleration of natural age-dependent $\mathrm{Mg}$ depletion suggesting that these ionic changes may be clinically significant, underlying the predisposition in elderly subjects to cardiovascular and metabolic diseases, and might therefore help to explain the age-related increased incidence of these diseases [30,54] (Fig. 3). Lower $\mathrm{Mg}$ levels may not only be a consequence, but may also predispose to diabetes. In a national population-based crosssectional nutrition survey in Taiwan, hypomagnesemia was associated with an increased risk of diabetes. Thus, the risk of diabetes was elevated 3.25 times at plasma $\mathrm{Mg}$ levels lower than $<0.863 \mathrm{mmol} / \mathrm{L}$ [55].

The link between Mg deficiency and the development of insulin resistance and type 2 diabetes is strengthened by the observation that several treatments for diabetes appear to increase $\mathrm{Mg}$ levels. Metformin, for example, raises Mg levels in the liver [56]. Pioglitazone, a thiazolidinedione antidiabetic agent that increases insulin sensitivity have positive actions on $\mathrm{Mg}$ metabolism both in vitro, and in vivo stimulating free $\mathrm{Mg}$ concentration in adipocytes [20] and increasing serum $\mathrm{Mg}$ in subjects who received pioglitazone [57]. Other insulin mimeting substances such as vanadate and IGF-1 are also associated to a direct effect to stimulate Mgi levels [58], and the effects of antioxidants glutathione and vitamin $\mathrm{E}$ to improve glucose and insulin metabolism may derive, at least in part, from their action on $\mathrm{Mg}$ metabolism [50,51]. The effects of glutathione on peripheral insulin sensitivity are associated to a specific action of glutathione to increase intracellular $\mathrm{Mg}$, and with a direct relation of euglycemic clamp-derived glucose disposal (WBGD) indices in vivo with intracellular Mg levels [50] (Fig. 4).

Altogether, independent to the cause of poor plasma and intracellular $\mathrm{Mg}$ content, a depletion of $\mathrm{Mg}$ seems to be a

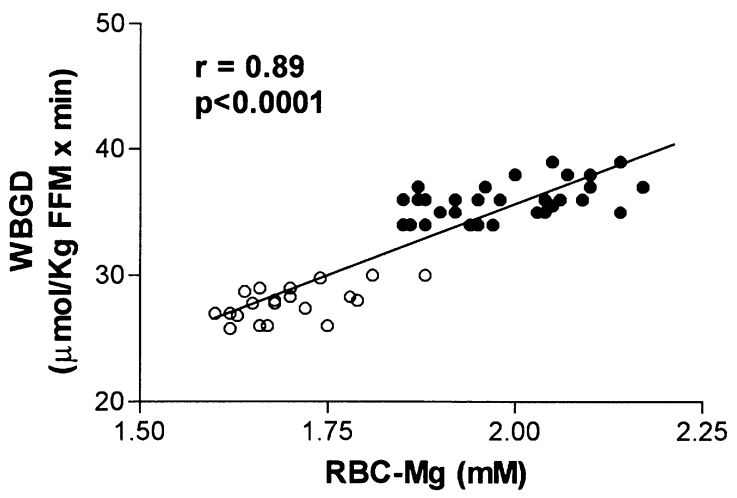

Fig. 4. Relations of whole body glucose disposal (WBGD) to intracellular $\mathrm{Mg}$. The relation to WBGD was also true when hypertensive (empty circles), and normotensive (full circles) subgroups were analyzed individually (normotensives: $r=0.50, P<0.01$; hypertensives: $r=0.56, P<0.01$ ). FFM indicates fat-free mass (Ref. [49]).

cofactor for a further derangement of insulin resistance $[1,59]$. Mg deficiency, which may take the form of a chronic latent $\mathrm{Mg}$ deficit rather than clinical hypomagnesemia, may have clinical importance because of the crucial role of $\mathrm{Mg}$ as a cofactor in many enzymatic reactions regulating glucose metabolism. A deficient $\mathrm{Mg}$ status may not just be a secondary consequence of type 2 diabetes but may precedes and cause itself insulin resistance and altered glucose tolerance, and even type 2 diabetes $[1,8,29]$. We have suggested a role for $\mathrm{Mg}$ deficit as a possible unifying mechanism of the of conditions associated to "insulin resistance", including type 2 diabetes mellitus, metabolic syndrome, essential hypertension $[1,53,54]$ (Fig. 1).

\section{Magnesium deficiency and vascular diabetic complications}

$\mathrm{Mg}$ deficiency has been proposed as a factor implicated in the pathogenesis of diabetes complications. Cellular ionic alterations are related to the cardiovascular structural alterations often present in diabetes. A significant relation was found between fasting levels of Mgi levels and cardiovascular structural indices [31]. In diabetic subjects, even in the absence of elevated blood pressure, suppressed Mgi levels are associated with cardiac hypertrophy, and specifically with increased echocardiographically measured posterior wall thickness and left ventricular mass index in both diabetic and/or hypertensive subjects [31]. When combined, hypertension and diabetes were associated with further deviated ion levels and a greater extent of cardiac hypertrophy. Similarly, magnetic resonance imaging (MRI) - determined values for aortic distensibility in normal and hypertensive humans were closely and positively related to concomitantly measured levels of Mgi measured in situ in brain and skeletal muscle tissue by ${ }^{31} \mathrm{P}$ NMR magnetic resonance spectroscopic (MRS) techniques: the more suppressed the Mgi, the stiffer (less distensible) the aorta [60]. In children and adolescent patients with type 1 diabetes, serum $\mathrm{Mg}$ levels have been associated with early atherosclerosis, and a significant relationships was found between 
serum $\mathrm{Mg}$ levels with intima-media thickness, and functions of common carotid artery, accepted as markers of early carotid atherosclerosis [61]. In patients with type 2 diabetes mellitus, low circulating $\mathrm{Mg}$ levels have been associated also with a more rapid decline of renal function [62]. To confirm the potential role of $\mathrm{Mg}$ deficits in the pathogenesis of diabetic vascular complications, in an experimental model of diabetes in rats, Soltani has recently suggested a potential role for oral $\mathrm{Mg}$ supplementation in the prevention of the vascular complications of the disease [63,64], and of the pathological changes in the aorta and pancreas of diabetic rats [65]. $\mathrm{Mg}$ may also be related to altered thermal pain threshold in diabetes. Thus, oral Mg administration given at the time of diabetes induction was able to restore thermal hyperalgesia, $\mathrm{Mg}$ deficiency and hyperglycemia in diabetic rats [66].

\section{Magnesium metabolism and the metabolic syndrome}

The presence of a metabolic syndrome is also associated with altered Mg metabolism [67-69]. Corica et al. recently showed that type 2 diabetics having a high risk lipid profile, high blood pressure or abdominal adiposity had lower circulating ionized $\mathrm{Mg}$ levels with respect to patients without metabolic risk factors. Furthermore, plasma triglycerides and waist circumference are independently associated with hypomagnesemia [68]. Guerrero-Romero found an interaction among $\mathrm{Mg}$ levels, risk for metabolic syndrome and inflammation and oxidative stress [69]. Decreased serum $\mathrm{Mg}$ levels have been found in the insulin resistance associated to nonalcoholic steatohepatitis (NASH) in obese subjects [70].

Since, hypomagnesemia may contribute to the pathophysiology of cardiovascular diabetes complications by altering blood lipid profile in a way that predispose to atherosclerosis, the association of $\mathrm{Mg}$ depletion with metabolic syndrome may offer another mechanism by which an alteration of $\mathrm{Mg}$ homeostasis may favour the onset and progression of diabetic complications. In agreement with this, oral $\mathrm{Mg}$ supplementation in patients with type 2 diabetes resulted in a significant decrease in total and LDL cholesterol, and an increase in HDL cholesterol [71]. Huerta et al. recently reported serum and dietary $\mathrm{Mg}$ deficiency in obese, insulin resistant nondiabetic children. Both serum and dietary $\mathrm{Mg}$ were inversely correlated with fasting insulin [72]. In postmenopausal non diabetic women intracellular $\mathrm{Mg}$ was found to be directly related with insulin sensitivity, body composition and free fat mass [73], confirming that both $\mathrm{Mg}$ deficit and obesity may independently lead to a higher risk for insulin resistance and cardiovascular disease [73].

$\mathrm{He}$ et al. have prospectively examined the relations between $\mathrm{Mg}$ intake and incident metabolic syndrome and its components among 4637 Americans, aged 18-30 years, who were free from metabolic syndrome and diabetes at baseline. During the 15 years of follow-up, 608 incident cases of the metabolic syndrome were identified. $\mathrm{Mg}$ intake was inversely associated with incidence of metabolic syn- drome after adjustment for major lifestyle and dietary variables and baseline status of each component of the metabolic syndrome. $\mathrm{Mg}$ intake was also inversely related to individual component of the metabolic syndrome and fasting insulin levels, suggesting that higher $\mathrm{Mg}$ intake may protect against the risk of development of metabolic syndrome [74].

\section{Role of dietary magnesium deficiency on insulin resistance and possible therapeutical effects of Mg supplements in DM2}

The hypothesis that alterations of $\mathrm{Mg}$ metabolism would induce and/or exacerbate insulin resistance is confirmed by data, in both humans and experimental animals, showing that dietary-induced $\mathrm{Mg}$ deficiency is correlated with insulin resistance [74-80]. A Mg-deficient diet in sheep has been found to be associated with a significant impairment of insulin-mediated glucose uptake [75] while Mg supplementation delayed the development of diabetes in a rat model of diabetes [76]. Higher $\mathrm{Mg}$ intake is associated with lower fasting insulin concentrations among women without diabetes [77], and a significant negative correlation is present between total dietary $\mathrm{Mg}$ intake and the insulin responses to an oral glucose tolerance test [78]. Rats fed a low $\mathrm{Mg}$ diet showed a significant increase in blood glucose and triglyceride levels [79]. Suarez et al. investigated the effect of dietary-induced $\mathrm{Mg}$ deficiency on glucose disposal, glucose-stimulated insulin secretion and insulin action on skeletal muscle in rats, which were fed a low Mg-containing diet. $\mathrm{Mg}$ depletion provoked a deleterious effect on glucose metabolism due to an impairment of both insulin secretion and action. In rats, maternal $\mathrm{Mg}$ restriction induces insulin resistance in pups by six months of age, whereas additional perinatal $\mathrm{Mg}$ deficiency impairs glucose tolerance [80]. The insulin resistance observed in skeletal muscle of Mg-deficient rats was linked, at least in part, to a defective tyrosinekinase activity of insulin receptors [81]. $\mathrm{Mg}$ intake is related not only to insulin sensitivity but also to the development of diabetes. Deficiencies of both dietary $\mathrm{Mg}$ and serum plasma $\mathrm{Mg}$ content have been associated with an increased risk to develop glucose intolerance and diabetes $[33,38,82,83]$ an increased $\mathrm{Mg}$ intake is associated with a significant decline in the incidence of type 2 diabetes [84]. Recent epidemiological data have shown a significant inverse association between $\mathrm{Mg}$ intake and diabetes risk supporting the priority of $\mathrm{Mg}$ deficit in the development of insulin resistance, metabolic syndrome and diabetes [74,85,86]. 85,060 women and 42,872 men, who had no history of diabetes or cardiovascular disease at baseline, had been followed, respectively, for 18 (women) and 12 (men) years, and the risk for type 2 diabetes in the upper quintile of $\mathrm{Mg}$ intake, as compared to that in the bottom quintile, was about a third lower after adjustment for a number of potentially confounding variables; and there was a significant inverse association between $\mathrm{Mg}$ intake and diabetes risk [85]. In the Women's Health Study, a cohort of 39,345 United States women aged $\geqslant 45$ years with no previous 
history of cardiovascular disease, cancer, or type 2 diabetes were followed for an average of six years. 918 confirmed incident cases of type 2 diabetes were documented, and a significant inverse association was found between $\mathrm{Mg}$ intake and risk of type 2 diabetes, independent of age and $\mathrm{BMI}$, supporting a protective role of higher intake of $\mathrm{Mg}$ in reducing the risk of developing type 2 diabetes [86].

Thus, taking into account that hypomagnesaemia has been associated with an increased risk to develop glucose intolerance and diabetes [38], the use of $\mathrm{Mg}$ supplements could be an alternative tool for the prevention of type 2 diabetes and metabolic syndrome, a hypothesis that needs to be confirmed by specific and well designed trials with $\mathrm{Mg}$ $[87,88]$. However, the effects of Mg supplements on the metabolic profile of diabetic subjects are controversia [89], benefits having been found in some [90-92], but not all clinical studies [93]. Differences in baseline $\mathrm{Mg}$ status and metabolic control may explain the differences among these studies. $\mathrm{Mg}$ may mediate the favorable impact of whole grains on insulin sensitivity cereal on insulin sensitivity [94-97].

A recent clinical trial specifically conducted among type 2 diabetes with low MgT levels (index of an already advanced $\mathrm{Mg}$ deficit) found a beneficial effect of oral $\mathrm{Mg}$ supplementation on fasting and postprandial glucose levels and insulin sensitivity [89], and we have shown an improvement in insulin-mediated glucose uptake measured by euglycemic insulin clamp and a significant relationship between the parallel increase in plasma and erythrocyte $\mathrm{Mg}$ concentration and the progressive increase in the insulin sensitivity in diabetic patients that were supplemented with increased dosage of $\mathrm{Mg}$ supplements [8]. Among non-diabetic, apparently healthy subjects there are also some evidences of a relatively small but significant beneficial effects of $\mathrm{Mg}$ supplements on insulin sensitivity [90]. The fact that most but not all diabetic subjects have a Mg deficiency and that no large clinical trial have been specifically focused on subjects with a $\mathrm{Mg}$ deficit, diagnosed with an accurate and reliable technique, may help to explain the discrepancy between the unclear role of supplemental $\mathrm{Mg}$ on glycemic control in diabetics, and the significant impact on diabetes risk in prospective epidemiologic studies [85]. Longer-term therapeutic trials of $\mathrm{Mg}$ in diabetes mellitus are clearly needed in the near future to narrow this gap.

\section{Conclusions}

Altogether, these accumulating evidence confirm (a) the critical importance of $\mathrm{Mg}$ metabolism in regulating insulin action and sensitivity (pathophysiologically, $\mathrm{Mg}$ depletion can directly cause tissutal insulin resistance); (b) that $\mathrm{Mg}$ deficiency, defined on the basis of intracellular free $\mathrm{Mg}$ levels, and or serum ionized $\mathrm{Mg}$ ( $\mathrm{Mg}$-ion) is a common feature of type 2 diabetes mellitus, metabolic syndrome and other insulin resistant states; (c) the possible role of cellular $\mathrm{Mg}$ as a underlying common mechanism of the "insulin resistance" of metabolic diseases including the metabolic syndrome, essential hypertension, altered glucose tolerance, and type 2 diabetes; (d) that low dietary $\mathrm{Mg}$ intake is related not only to insulin sensitivity but also to the development of type 2 diabetes mellitus, and that further prospective studies are needed to support the potential role of dietary $\mathrm{Mg}$ supplementation as a possible public health strategy to reduce diabetes risk in the population.

\section{References}

[1] M. Barbagallo, L.J. Dominguez, A. Galioto, A. Ferlisi, C. Cani, L. Malfa, A. Pineo, A. Busardo, G. Paolisso, Mol. Aspects Med. 24 (2003) 39-52.

[2] N.E. Saris, E. Mervaala, H. Karppanen, J.A. Khawaja, A. Lewenstam, Clin. Chim. Acta 294 (2000) 1-26.

[3] L.M. Resnick, B.T. Altura, R.K. Gupta, J.H. Laragh, M.H. Alderman, B.M. Altura, Diabetologia 36 (1993) 767-770.

[4] B.T. Altura, J.L. Burack, R.Q. Cracco, L. Galland, S.M. Handwerker, M.S. Markell, A. Mauskop, Z.S. Memon, L.M. Resnick, Z. Zisbrod, et al., Scand. J. Clin. Lab. Invest. Suppl. 217 (1994) 53-67.

[5] R.K. Gupta, P. Gupta, R.D. Moore, Annu. Rev. Biophys. Bioeng. 13 (1984) 221-246.

[6] L.M. Resnick, R.K. Gupta, J.H. Laragh, Proc. Natl. Acad. Sci. USA 81 (1984) 6511-6515.

[7] P. Delva, C. Pastori, M. Degan, G. Montesi, A. Lechi, J. Membr. Biol. 199 (2004) 163-171.

[8] G. Paolisso, M. Barbagallo, Am. J. Hypertens. 10 (1997) 346-355.

[9] M. Barbagallo, R.K. Gupta, L.M. Resnick, Diabetologia 36 (1993) 146-149.

[10] B. Draznin, J.W. Leitner, K.E. Sussman, N.A. Sherman, Biochem. Biophys. Res. Commun. 156 (1988) 570-575.

[11] M.F. McCarty, Med. Hypotheses 66 (2006) 824-831.

[12] D.L. Hwang, C.F. Yen, J.L. Nadler, J. Clin. Endocrinol. Metab. 76 (1993) 549-553.

[13] C. Vidair, H. Rubin, Proc. Natl. Acad. Sci. USA 102 (2005) 662-666.

[14] H. Rubin, Adv. Cancer Res. 93 (2005) 1-58.

[15] B.M. Altura, B.T. Altura, A. Carella, Science 221 (1983) 376-378.

[16] R.R. Ettarh, A.P. Arikawe, Magnes. Res. 17 (2004) 270-275.

[17] O.G. Kolterman, R.S. Gray, J. Griffin, P. Burstein, J. Insel, J.A. Scarlett, J.M. Olefsky, J. Clin. Invest. 68 (1981) 957-969.

[18] T. Naitoh, S. Kobayashi, I. Kimura, M. Kimura, Jpn. J. Pharmacol. 56 (1991) 241-244.

[19] R. Paxton, L. Ye, Mol. Cell. Biochem. 277 (2005) 7-17.

[20] J. Nadler, S. Scott, Biochem. Biophys. Res. Commun. 202 (1994) 416421.

[21] M.R. Laughlin, D. Thompson, J. Biol. Chem. 271 (1996) 28977-28983.

[22] L.M. Resnick, O. Bardicef, M. Barbagallo, et al., Hypertension 26 (1995) 552.

[23] L.M. Resnick, M. Barbagallo, R.K. Gupta, J.H. Laragh, Am. J. Hypertens. 6 (1993) 413-417.

[24] M. Barbagallo, L.J. Dominguez, O. Bardicef, L.M. Resnick, Hypertension 38 (2001) 612-615.

[25] L.M. Resnick, R.K. Gupta, K.K. Bhargava, H. Gruenspan, M.H. Alderman, J.H. Laragh, Hypertension 17 (1991) 951-957.

[26] M. Barbagallo, J. Shan, P.K. Pang, L.M. Resnick, J. Clin. Invest. 95 (1995) 763-767.

[27] R. Klauser, R. Prager, G. Schernthaner, J.M. Olefsky, J. Clin. Endocrinol. Metab. 73 (1991) 758-764.

[28] B.M. Altura, B.T. Altura, Fed. Proc. 40 (1981) 2672-2679.

[29] M. Barbagallo, L.J. Dominguez, L.M. Resnick, Am. J. Ther. 13 (2006) in press.

[30] M. Barbagallo, R.K. Gupta, L.J. Dominguez, L.M. Resnick, J. Am. Geriatr. Soc. 48 (2000) 1111-1116.

[31] M. Barbagallo, R.K. Gupta, L.M. Resnick, Diabetes Care 19 (1996) 1393-1398.

[32] M. Barbagallo, R.K. Gupta, O. Bardicef, M. Bardicef, L.M. Resnick, J. Clin. Endocrinol. Metab. 82 (1997) 1761-1765. 
[33] H.M. Mather, J.A. Nisbet, G.H. Burton, G.J. Poston, J.M. Bland, P.A. Bailey, T.R. Pilkington, Clin. Chim. Acta 95 (1979) 235-242.

[34] W.F. Vanroelen, L.F. Van Gaal, P.E. Van Rooy, I.H. De Leeuw, Acta Diabetol. Lat. 22 (1985) 185-190.

[35] C. Schnack, I. Bauer, P. Pregant, P. Hopmeier, G. Schernthaner, Diabetologia 35 (1992) 77-79.

[36] M.K. Walti, M.B. Zimmermann, G.A. Spinas, R.F. Hurrell, Swiss Med. Wkly. 133 (2003) 289-292.

[37] M.K. Walti, M.B. Zimmermann, T. Walczyk, G.A. Spinas, R.F. Hurrell, Am. J. Clin. Nutr. 78 (2003) 448-453.

[38] W.H. Kao, A.R. Folsom, F.J. Nieto, J.P. Mo, R.L. Watson, F.L. Brancati, Arch. Intern. Med. 159 (1999) 2151-2159.

[39] P. McNair, M.S. Christensen, C. Christiansen, S. Madsbad, I. Transbol, Eur. J. Clin. Invest. 12 (1982) 81-85.

[40] M.S. Djurhuus, P. Skott, O. Hother-Nielson, N.A. Klitgaard, H. BeckNielsen, Diabet. Med. 12 (1995) 664-669.

[41] C.T. Lee, Y.H. Lien, L.W. Lai, J.B. Chen, C.R. Lin, H.C. Chen, Kidney Int. (2006).

[42] J. Takaya, H. Higashino, F. Kotera, Y. Kobayashi, Metabolism 52 (2003) 468-471.

[43] E. Simsek, M. Karabay, K. Kocabay, Turk. J. Pediatr. 47 (2005) 132 137.

[44] L. Lima Mde, J. Pousada, C. Barbosa, T. Cruz, Arq. Bras. Endocrinol. Metabol. 49 (2005) 959-963.

[45] C. Cefaratti, A. Romani, Metabolism 52 (2003) 1464-1470.

[46] C. Cefaratti, A. McKinnis, A. Romani, Mol. Cell. Biochem. 262 (2004) $145-154$.

[47] T.E. Fagan, C. Cefaratti, A. Romani, Am. J. Physiol. Endocrinol. Metab. 286 (2004) E184-E193.

[48] L.M. Resnick, M. Barbagallo, M. Bardicef, O. Bardicef, Y. Sorokin, J. Evelhoch, L.J. Dominguez, B.A. Mason, D.B. Cotton, Hypertension 44 (2004) 322-326.

[49] L.M. Resnick, R.K. Gupta, H. Gruenspan, M.H. Alderman, J.H. Laragh, Am. J. Hypertens. 3 (1990) 373-379.

[50] M. Barbagallo, L.J. Dominguez, M.R. Tagliamonte, L.M. Resnick, G. Paolisso, Hypertension 34 (1999) 76-82.

[51] M. Barbagallo, L.J. Dominguez, M.R. Tagliamonte, L.M. Resnick, G. Paolisso, Hypertension 34 (1999) 1002-1006.

[52] H. Rosolova, O. Mayer Jr., G.M. Reaven, Metabolism 49 (2000) 418 420.

[53] L.M. Resnick, Prog. Cardiovasc. Dis. 42 (1999) 1-22.

[54] M. Barbagallo, L.M. Resnick, Calcium and Magnesium in the Regulation of Smooth Muscle Function and Blood Pressure: The Ionic Hypothesis of Cardiovascular and Metabolic Diseases and Vascular Aging, Humana Press Inc, NJ, 1996, 283-300 pp.

[55] J.L. Wang, N.S. Shaw, H.Y. Yeh, M.D. Kao, Asia Pac. J. Clin. Nutr. 14 (2005) 263-269.

[56] S.A. Ewis, M.S. Abdel-Rahman, J. Appl. Toxicol. 15 (1995) 387-390.

[57] F. Guerrero-Romero, M. Rodriguez-Moran, Exp. Clin. Endocrinol. Diabetes 111 (2003) 91-96.

[58] L.J. Dominguez, M. Barbagallo, J.R. Sowers, L.M. Resnick, J. Clin. Endocrinol. Metab. 83 (1998) 4402-4407.

[59] J. Takaya, H. Higashino, Y. Kobayashi, Magnes. Res. 17 (2004) 126 136.

[60] L.M. Resnick, D. Militianu, A.J. Cunnings, J.G. Pipe, J.L. Evelhoch, R.L. Soulen, M.A. Lester, Am. J. Hypertens. 13 (2000) 1243-1249.

[61] M.E. Atabek, S. Kurtoglu, O. Pirgon, M. Baykara, Diabetes Res. Clin. Pract. (2005).

[62] P.C. Pham, P.M. Pham, P.A. Pham, S.V. Pham, H.V. Pham, J.M. Miller, N. Yanagawa, P.T. Pham, Clin. Nephrol. 63 (2005) 429-436.

[63] N. Soltani, M. Keshavarz, H. Sohanaki, S. Zahedi Asl, A.R. Dehpour, Eur. J. Pharmacol. 508 (2005) 177-181.

[64] N. Soltani, M. Keshavarz, H. Sohanaki, A.R. Dehpour, S.Z. Asl, Life Sci. 76 (2005) 1455-1464.
[65] N. Soltani, M. Keshavarz, B. Minaii, F. Mirershadi, S.Z. Asl, A.R. Dehpour, Clin. Exp. Pharmacol. Physiol. 32 (2005) 604-610.

[66] P. Hasanein, M. Parviz, M. Keshavarz, K. Javanmardi, M. Mansoori, N. Soltani, Diabetes Res. Clin. Pract. (2006).

[67] F. Guerrero-Romero, M. Rodriguez-Moran, Acta Diabetol. 39 (2002) 209-213.

[68] F. Corica, A. Corsonello, R. Ientile, D. Cucinotta, A. Di Benedetto, F. Perticone, L.J. Dominguez, M. Barbagallo, J. Am. Coll. Nutr. 25 (2006) 210-215.

[69] F. Guerrero-Romero, M. Rodriguez-Moran, Diabetes Metab. Res. Rev. (2006).

[70] H. Rodriguez-Hernandez, J.L. Gonzalez, M. Rodriguez-Moran, F. Guerrero-Romero, Arch. Med. Res. 36 (2005) 362-366.

[71] F. Corica, A. Allegra, A. Di Benedetto, M.S. Giacobbe, G. Romano, D. Cucinotta, M. Buemi, D. Ceruso, Magnes. Res. 7 (1994) 43-47.

[72] M.G. Huerta, J.N. Roemmich, M.L. Kington, V.E. Bovbjerg, A.L. Weltman, V.F. Holmes, J.T. Patrie, A.D. Rogol, J.L. Nadler, Diabetes Care 28 (2005) 1175-1181.

[73] M.J. Laires, H. Moreira, C.P. Monteiro, L. Sardinha, F. Limao, L. Veiga, A. Goncalves, A. Ferreira, M. Bicho, J. Am. Coll. Nutr. 23 (2004) 510 S-513S.

[74] K. He, K. Liu, M.L. Daviglus, S.J. Morris, C.M. Loria, L. Van Horn, D.R. Jacobs Jr., P.J. Savage, Circulation 113 (2006) 1675-1682.

[75] S. Matsunobu, Y. Terashima, T. Senshu, H. Sano, H. Itoh, J. Nutr. Biochem. 1 (1990) 167-171.

[76] T.W. Balon, J.L. Gu, Y. Tokuyama, A.P. Jasman, J.L. Nadler, Am. J. Physiol. 269 (1995) E745-E752.

[77] T.T. Fung, J.E. Manson, C.G. Solomon, S. Liu, W.C. Willett, F.B. Hu, J. Am. Coll. Nutr. 22 (2003) 533-538.

[78] S. Humphries, H. Kushner, B. Falkner, Am. J. Hypertens. 12 (1999) 747-756.

[79] D.P. Chaudhary, R.K. Boparai, R. Sharma, D.D. Bansal, Magnes. Res. 17 (2004) 293-300.

[80] L. Venu, Y.D. Kishore, M. Raghunath, J. Nutr. 135 (2005) 1353-1358.

[81] A. Suarez, N. Pulido, A. Casla, B. Casanova, F.J. Arrieta, A. Rovira, Diabetologia 38 (1995) 1262-1270.

[82] K. Yokota, Clin. Calcium 15 (2005) 203-212.

[83] D.A. Longstreet, D.L. Heath, R. Vink, Med. J. Aust. 183 (2005) 219-220.

[84] G.A. Colditz, J.E. Manson, M.J. Stampfer, B. Rosner, W.C. Willett, F.E. Speizer, Am. J. Clin. Nutr. 55 (1992) 1018-1023.

[85] R. Lopez-Ridaura, W.C. Willett, E.B. Rimm, S. Liu, M.J. Stampfer, J.E. Manson, F.B. Hu, Diabetes Care 27 (2004) 134-140.

[86] Y. Song, J.E. Manson, J.E. Buring, S. Liu, Diabetes Care 27 (2004) $59-65$.

[87] M.F. McCarty, Med. Hypotheses 64 (2005) 151-158.

[88] M.B. Schulze, F.B. Hu, Annu. Rev. Public Health 26 (2005) 445-467.

[89] F. Guerrero-Romero, M. Rodriguez-Moran, Arch. Med. Res. 36 (2005) 250-257.

[90] F. Guerrero-Romero, H.E. Tamez-Perez, G. Gonzalez-Gonzalez, A.M. Salinas-Martinez, J. Montes-Villarreal, J.H. Trevino-Ortiz, M. Rodriguez-Moran, Diabetes Metab. 30 (2004) 253-258.

[91] M. Rodriguez-Moran, F. Guerrero-Romero, Diabetes Care 26 (2003) $1147-1152$.

[92] K. Yokota, M. Kato, F. Lister, H. Ii, T. Hayakawa, T. Kikuta, S. Kageyama, N. Tajima, J. Am. Coll. Nutr. 23 (2004) 506S-509S.

[93] H.W. de Valk, R. Verkaaik, H.J. van Rijn, R.A. Geerdink, A. Struyvenberg, Diabet. Med. 15 (1998) 503-507.

[94] M.F. McCarty, Med. Hypotheses 64 (2005) 619-627.

[95] M.O. Weickert, M. Mohlig, C. Schofl, A.M. Arafat, B. Otto, H. Viehoff, C. Koebnick, A. Kohl, J. Spranger, A.F. Pfeiffer, Diabetes Care 29 (2006) 775-780.

[96] A.D. Liese, A.K. Roach, K.C. Sparks, L. Marquart, R.B. D'Agostino Jr., E.J. Mayer-Davis, Am. J. Clin. Nutr. 78 (2003) 965-971.

[97] N.M. McKeown, Nutr. Rev. 62 (2004) 286-291. 